\title{
Does distance hinder the collaboration between Australian Universities in the Humanities, Arts and Social Sciences?
}

\section{Qingzhou Luo}

School of Geography and Remote Sensing, Nanjing University of Information Science and Technology, Nanjing 210044, China

\section{Jianhong (Cecilia) Xia*}

School of Earth and Planetary Sciences, Curtin University, GPO Box U1987, Perth, Western Australia, Australia c.xia@curtin.edu.au P: + 61892667563

* Corresponding Author

\section{Gaby Haddow}

School of Media, Creative Arts \& Social Inquiry, Curtin University, GPO Box U1987, Perth, Western Australia, Australia.

\section{Michele Willson}

School of media, Creative Arts and Social Inquiry, Curtin University, GPO Box U1987, Perth, Western Australia, Australia

\section{Jun Yang}

Human Settlements Research Center, Liaoning Normal University, Dalian, Liaoning Province, P.R. China 116029

\footnotetext{
Abstract

Australia is a vast country with an average distance of 1911 kilometres between its eight state capital cities. The quantitative impact of this distance on collaboration practices between Australian universities and between different types of Australian universities has not been examined previously and hence our knowledge about the spatial distribution effects, if any, on collaboration practices and opportunities is very limited. The aim of the study reported here was therefore to analyse the effect of distance on the collaboration activities of humanities, arts and social science (HASS) scholars in Australia, using co-authorship as a proxy for collaboration.

In order to do this, gravity models were developed to determine the distance effects on external collaboration between universities in relation to geographic region and institutional alliance of 25 Australian universities. Although distance was found to have a weak impact on external collaboration, the strength of the research publishing record within a university (internal collaboration) was found to be an important factor in determining external collaboration activity levels. This finding would suggest that increasing internal collaboration within universities could be an effective strategy to encourage external collaboration between universities. This strategy becomes even more effective for universities that are further away
} 
from each other. Establishing a hierarchical structure of different types of universities within a region can optimise the location advantage in the region to encourage knowledge exchange within that region. The stronger network could also attract more collaboration between networks.

Keywords: distance decay; Australian universities; internal and external collaboration; institutional alliance; geographical proximity; onion model.

\section{Introduction}

Australia is a vast country with an average distance of 1911 kilometres between its eight state capital cities: Sydney, Melbourne, Brisbane, Canberra, Adelaide, Perth, Darwin and Hobart. However, the population numbers are relatively small with the populace primarily living in and around the major cities. These large distances and low population densities have the potential to create geographical barriers to collaboration activities between Australian universities. Moreover, in a study of co-authorship, the humanities, arts and social science disciplines (HASS) have been found to collaborate at lower levels than the science fields, with much higher sole authored publication numbers than co-authored publications being produced. For example, Haddow, Xia and Willson (2017) found that 61.1 per cent of HASS publications were sole authored, based on a set of 21,217 records. Collaboration between HASS researchers at Australian universities was 26.1 per cent, and 12.8 per cent of the publications were collaborations between Australian and international partners. Currently, the quantitative impact of distance on collaboration between Australian universities (and between the different types of Australian universities) has not been reported and our knowledge about the spatial distribution of collaboration activities by Australian universities in HASS is very limited (Turner \& Brass, 2014). A better understanding of the impact that distance has on collaboration by Australian HASS researchers has the potential to inform strategy and policymaking decisions for increasing strong collaboration in Australia.

Using co-authorship as a proxy for collaboration, this study analysed the spatial distribution pattern of Australian universities in order to measure the impact of the distance between universities' geographical region and type of university on HASS collaboration within (internal) and between (external) university groups. Two research questions were developed:

1. Does distance have a statistically significant impact on HASS collaboration between Australian universities?

2. Does university type (institutional alliance or network) influence the impact of distance on HASS collaboration between Australian universities?

In order to achieve the primary aim, three research objectives were derived: 1) To analyse the spatial distribution pattern of collaboration between Australian universities in HASS using Geographical Information Systems (GIS) methods; 2) To calculate the correlation between distance and the number of collaborations between Australian universities from three perspectives: a) distance, b) geographical region based on an onion model, and c) institutional alliances; and 3) To measure the relationship between distance and collaboration by Australian universities using the zero-inflated poisson regression model. 


\section{Literature review}

The value of collaboration to the higher education sector is well documented and researched (see for example, Beaver, 2001; Katz \& Martin, 1997; Luukkonen, Persson \& Sivertsen, 1992; Moed, 2005; Sonnenwald, 2007; The Royal Society, 2011). With its potential for delivering innovation, efficiencies and improved university rankings, collaborative research is encouraged by funding agencies and institutions alike (Australian Research Council, 2015; Hoekman, Frenken \& van Oort, 2009; Katz \& Martin, 1997; Sonnenwald, 2007).

Collaborating researchers benefit from sharing expertise and skills, and collaborating authors are likely to accumulate more citations than sole authors, particularly if the collaboration is international (Katz \& Martin, 1997; Pan et al., 2011; Sonnenwald, 2007; The Royal Society, 2011).

Research into collaboration more generally has found "a continuous increase in the number of co-authored papers in every scientific discipline" (Sonnenwald, 207, p. 643), with the share of co-authored papers in the Web of Science database more than doubling in the last three decades (Waltman, Tijssen \& van Eck, 2011, p. 577). With the advent of technological tools that support virtual communication, collaboration across regions and countries has been made easier, however, distance - or proximity, in Boschma's (2005) terms - remains noted as an important factor in determining collaborative activities, either as a facilitator or barrier (Frenken, et al., 2009; Grabher \& Ibert, 2014; Lorigo \& Pellacini, 2007; Pallot, MartinezCarreras \& Prinz, 2010).

While case studies (Grabher \& Ibert, 2014), patents (Hoekman, Frenken \& van Oort, 2009) and citation patterns ( Pan et al., 2012) have been used to examine collaboration and distance, most research on the topic draws on co-authorship information from publications datasets, such as Web of Science. While this method of exploring collaboration does not account for the full range of potential collaboration activities that may lead to innovation and knowledge creation, it has an important advantage. Publications, or co-authored publications more specifically, are a tangible outcome of collaboration and provide affiliation data for the identification of institutions and, consequently, distance, which are central to many collaboration studies (Glänzel \& Schubert, 2005; Laudel, 2002).

The influence of distance on collaboration has been studied for many years (Katz, 1994), but in 2005, Boschma defined "five dimensions of proximity", which created a framework with which to examine aspects of collaboration more closely. Boschma's dimensions are cognitive, organizational, social, institutional and geographical. For the purposes of this paper, it is useful to note the definitions for two of these dimensions: "geographical proximity is defined as spatial distance between actors, both in an absolute and relative meaning" and institutional proximity relates to "the fact that interactions between players are influenced, shaped and constrained by the institutional environment" (Boschma, 2005, p. 63). Other approaches have included defining regions, within and across national boundaries, using geographical coordinates (Katz, 1994; Lorigo \& Pellacini, 2007; Scherngell \& Hu, 2011; Sidone, Haddad \& Mena-Chalco, 2017; Waltman, Tijssen \& van Eck, 2011), and combinations of these with Boschma's dimensions (Fernández, Ferrándiz \& Leon, 2016; Frenken, et al., 2009; Hoekman, Frenken \& Tijssen, 2010). 
Regardless of the approach, the research to date has consistently found that as distance increases collaboration decreases (see for example, Evans, 2011; Grabher \& Ibert, 2014; Frenken, et al., 2009; Hoekman, Frenken \& Tijssen, 2010; Hoekman, Frenken \& van Oort, 2009; Scherngell \& Hu, 2011; Sidone, Haddad \& Mena-Chalco, 2017). And although the average distance between collaborators has been increasing over the past thirty years (Hoekman, Frenken \& Tijssen, 2010, p. 663; Waltman, Tijssen \& van Eck, 2011, p. 576), the "relative frequency of remote collaborations" has tracked alongside publication numbers (Lorigo \& Pellacini, 2007, p. 1501), which suggests that new communications technologies have not had a major impact.

Boschma's proximity dimensions have been applied in some studies, as has the use of gravity models (Acosta, Coronado \& Ferrándiz, 2011; Evans, Lambiotte \& Panzarasa, 2011; Fernández, Ferrándiz, \& Leon, 2016; Frenken, et al., 2009; Hoekman, Frenken \& Tijssen, 2010; Hoekman, Frenken \& van Oort, 2009; Ponds, van Oort \& Frenken, 2007; Scherngell \& $\mathrm{Hu}, 2011$; Sidone, Haddad \& Mena-Chalco, 2017). A common finding is that publication numbers are positively associated with collaboration (Acosta, Coronado \& Ferrándiz, 2011; Frenken, et al., 2009; Fernández, Ferrándiz, \& Leon, 2016; Hoekman, Frenken \& Tijssen, 2010). That is, collaboration is likely to be higher when those collaborating (a country, region or institution) are more prolific publishers.

Research into the role of distance or proximity on collaboration has studied regions and countries, different types of institutions and organisations, and specific fields of interest. Collaboration globally, in Europe and European countries, the Americas, China, and Australia is the focus of the literature discussed in this paper. Countries of a similar geographical scale to Australia, China and Brazil, were investigated by Scherngell and $\mathrm{Hu}$ (2011) and Sidone, Haddad and Mena-Chalco (2017), respectively. These studies applied a number of models to test the impact of distance on the probability of collaboration. In the Brazilian study, the influence of research field was clearly identified as an additional effect on the probability of collaboration, while Scherngell and $\mathrm{Hu}$ (2011, p. 761) found "most of the relative strongest links correspond to collaborations between regions that are direct spatial neighbours", suggesting that this may be associated with movement of scholars between institutions with existing links. The role of institutions was also discussed by Ponds, van Oort and Frenken (2007) in their examination of co-authored publications by different types of science-based technology organisations in The Netherlands. The authors found "geographical proximity especially seems to matter for collaboration in the case of institutional differences" (Ponds, van Oort and Frenken, 2007, p. 442).

Collaboration in science fields occurs at higher rates than in the social sciences, and the social sciences collaborate more than humanities fields (see for example, Abramo, D'Angelo, \& Murgia, 2014; Bordons \& Gómez, 2000; Endersby, 1996; Larivière, Gingras, \& Archambault, 2006; Marshakova-Shaikevich, 2006; Ossenblok, Verleysen, \& Engels, 2014; Sidone, Haddad \& Mena-Chalco, 2017; Turner \& Brass, 2014). This is, in the main, related to scholarly communication practices in the HASS fields. An additional barrier to studying collaboration in fields outside of the sciences is the limited coverage of HASS fields by sources of data, such as Web of Science (Hicks, 1999, 2005; Moed, 2005). As a consequence, less research has been conducted into the influence of distance on HASS collaboration. A few studies have examined the topic across all disciplinary fields (for example, Hoekman, 
Frenken \& Tijssen, 2010; Scherngell \& Hu, 2011; Waltman, Tijssen \& van Eck, 2011), and Evans, Lambiotte and Panzarasa (2011) focused solely on business and management. According to Hoekman, Frenken and Tijssen (2010, p. 666), in comparison to other fields "collaboration in engineering, social sciences and especially the humanities are most heavily biased in all spatial dimensions". Scherngell and $\mathrm{Hu}$ (2011, p. 764) used the term 'distance decay' to define the influence of distance on collaboration, finding that social sciences publications were just under the average in relation to other fields. In another study, social science fields, but more particularly humanities fields, were found to occupy "the bottom of the list" of Mean Geographical Collaboration Distance (MGCD) across all fields (Waltman, Tijssen \& van Eck, 2011, p. 577).

Research into collaboration and distance in Australia is also limited, with only two relevant studies located (Katz, 1994; Waltman, Tijssen \& van Eck, 2011). Katz (1994, p. 39) explored geographical proximity in Australia, Canada and the United Kingdom (UK) and found that the influence of proximity was significant in Australia, but less than the other countries because the "geographical distribution of universities in Australia is more dispersed". The results showed that over 60 per cent of Australian inter-university collaborations take place within a "radius equal to less than 20 per cent of the country size" (Katz, 1994, p. 39). The percentage of Canadian collaborations was the same and the UK was the lowest, at 40 per cent. Using geographical location codes, Waltman, Tijssen and van Eck (2011, p. 579) identified the MGCD for fields and for countries and presented their findings in kilometres. Australia had the second highest MGCD at between 3,000 and 4,000 km; New Zealand was the highest.

As the above overview of the literature reveals, the quantitative impact of distance on HASS collaboration practices between Australian universities and between different types of Australian universities has not been examined previously and hence our knowledge about the spatial distribution effects, if any, on collaboration practices and opportunities is very limited. This, in turn, limits the ability of policy-makers to reach informed decisions about how to develop collaborative activities within the higher education sector in Australia.

The aim of this study is therefore to analyse the effect of distance on the collaboration activities of HASS scholars in Australia, using co-authorship as a proxy. In order to do this, spatial distribution patterns were identified for geographical, regional and institutional alliance for 25 Australian universities in order to determine the effects of these on scientific collaboration practices.

\section{Methods}

\subsection{The data collection method}

In this study, we classified 25 (out of a total of 41) Australian universities into three categories: 1) by their alliance or network; 2) by distance between universities; and 3) by location within a geographic region. Geographical distance was measured in kilometres. For the first two categories, alliance and distance, which are similar to Boschma's geographical 
and institutional proximity dimensions (2005), internal collaboration is defined as author collaboration within a university whereas external collaboration is defined as author collaboration between universities. For the category of geographic region, the internal collaboration is within the universities in the interior set or region, whereas the external collaboration is between universities in the interior set and universities in the exterior set based an onion theory. The detail can be seen in section 3.2.3. The 25 universities were chosen as they all belong to an established institutional alliance group (Australian Education Network, 2017). More details about these groups are discussed below.

Co-authored publications by Australian HASS scholars were used as a proxy for collaboration. A total of 21,217 publication records were retrieved from the Web of Science databases including Social Sciences Citation Index (SSCI), Arts \& Humanities Citation Index (A\&HCI), Conference Proceedings Citation Index-Social Science \& Humanities (CPCI$\mathrm{SSH}$ ), and the Book Citation Index-Social Sciences \& Humanities (BKCI-SSH) for the period 2004 to 2013. The search was limited to authors' affiliation addresses in Australia and research fields specific to HASS to collect the publications sample required. Details of the search strategy can be found in Haddow, Xia and Willson (2017).

Using data drawn from Web of Science has important benefits in a study of co-authorship, such as fields for affiliation that can be searched and assigned research areas that can be used to limit a search. However, the data set retrieved from this source is necessarily restricted to the publications that the database indexes. As a consequence, the sample of co-authored publications that comprise the data for this study is only a proportion of all publications produced by collaborating authors in Australian HASS. Moreover, book and book chapters will be represented in lesser numbers due to the indexing policy of the database.

The data were downloaded into a spreadsheet and cleaned to ensure institution names were consistent across the dataset. With this data source, a one-to-one collaboration within and between universities was derived. For example, for an article with 6 authors (3 Curtin University, 2 University of Melbourne, and 1 Monash University) the data was calculated as: (a) internal collaboration - the collaboration within universities: Curtin-Curtin 3 times, Melbourne-Melbourne 1 times; and (b) external collaboration - the collaboration between universities: Curtin-Melbourne 6 times, Curtin-Monash 3 times, Melbourne-Monash 2 times. The data used was confined to affiliations with the 25 universities. If the university affiliations of authors didn't belong to these 25 universities, we did not include them in the collaboration counting.

\subsection{Australian university categories}

\subsubsection{Australian university categories by their alliance types}

The 25 Australian universities are aligned with a group or alliance; this was an important selection criterion for choosing the universities to include in this study. These alliances are identified as follows: Group of Eight (Go8); Australian Technology Network (ATN); Innovative Research Universities (IRU); and Regional Universities Network (RUN) (see Figure 2). The groupings are based on historical, constituent or organisational similarities or concerns and as a result, the universities within an alliance would be expected to exhibit some level of cross institutional collaboration activity. 
The Go8 is a group of research-intensive Australian universities. They are the country's oldest universities and they perform the majority of research conducted by Australian universities. These universities are well connected internationally, and have strong links with the business and public sectors (Australia's Group of Eight, https://go8.edu.au). The ATN is a coalition of five newer universities, one from each mainland state (Tasmania is not represented in the ATN), that emphasize "industry collaboration, real-world research with real-world impact and produce work-ready graduates to become global thinkers in business and the community" (ATN 2016, p. 1). The IRU is an alliance of six comprehensive universities focussed on advocating Australian university policy that supports "excellence in teaching, learning and research global applicability" (IRU, 2016, p 1). The IRU universities enrol 14 per cent of the low socioeconomic status undergraduate population, educate 19 per cent of indigenous students enrolled at university, and 19 per cent of regional and remote undergraduate students (IRU, 2016). The RUN was established in October 2011 and is a group of six regional Australian universities that position their institutions as building regional economic, social, cultural and environmental development through the generation of knowledge, innovation, and professional skills (RUN 2016).

As noted above, internal collaboration for alliance groups is defined as author collaboration within a university in the same alliance, e.g. collaboration between Curtin authors - a member of the ATN. External collaboration is defined as author collaboration between universities in the same alliance group. The aim of this analysis is to understand if distance impacts on the collaboration within or between universities within each alliance university group.

\subsubsection{Australian university category by geographical distance}

We identified 300 university pairs (based on evidence of collaboration activity) from the 25 universities, with a distance that ranges from $0.17 \mathrm{~km}$ to $3644 \mathrm{~km}$ (See Figure 1). Based on the shape of cumulative probability of external collaboration between universities and the number of university pairs, three geographical distance sub-categories were defined (Figure 1). For these geographical distance sub-categories, the internal collaboration is average author collaboration within a university in a distance range, e.g. $0-25 \mathrm{~km}$. The external collaboration is author collaboration between universities in a distance range. The aim of this analysis is to understand how distance between the universities impacts on collaboration within or between universities in a distance range.

- $0-25 \mathrm{~km}$ (Collaboration between universities within the same city): the slope of the cumulative probability curve of external collaboration between universities is greater than that of the number of university pairs. This means that as distance increases, the growth rate of the external collaboration between universities is faster than the one of the number of university pairs. Total number of university pairs in this category is 18 .

- $25-1400 \mathrm{~km}$ : the slope of the cumulative probability curve of external collaboration is similar to that of the number of university pairs. This means that, as distance increases, the growth rate is similar between the external collaboration between universities and the number of university pairs. Total number of university pairs in this category is 149 . 
- $\quad>1400 \mathrm{~km}$ : the slope of the cumulative probability curve of external collaboration is less than that of the number of university pairs. As distance increase, the growth rate of the external collaboration between universities is slower than the one of the number of university pairs. Total number of university pairs in this category is 133 .

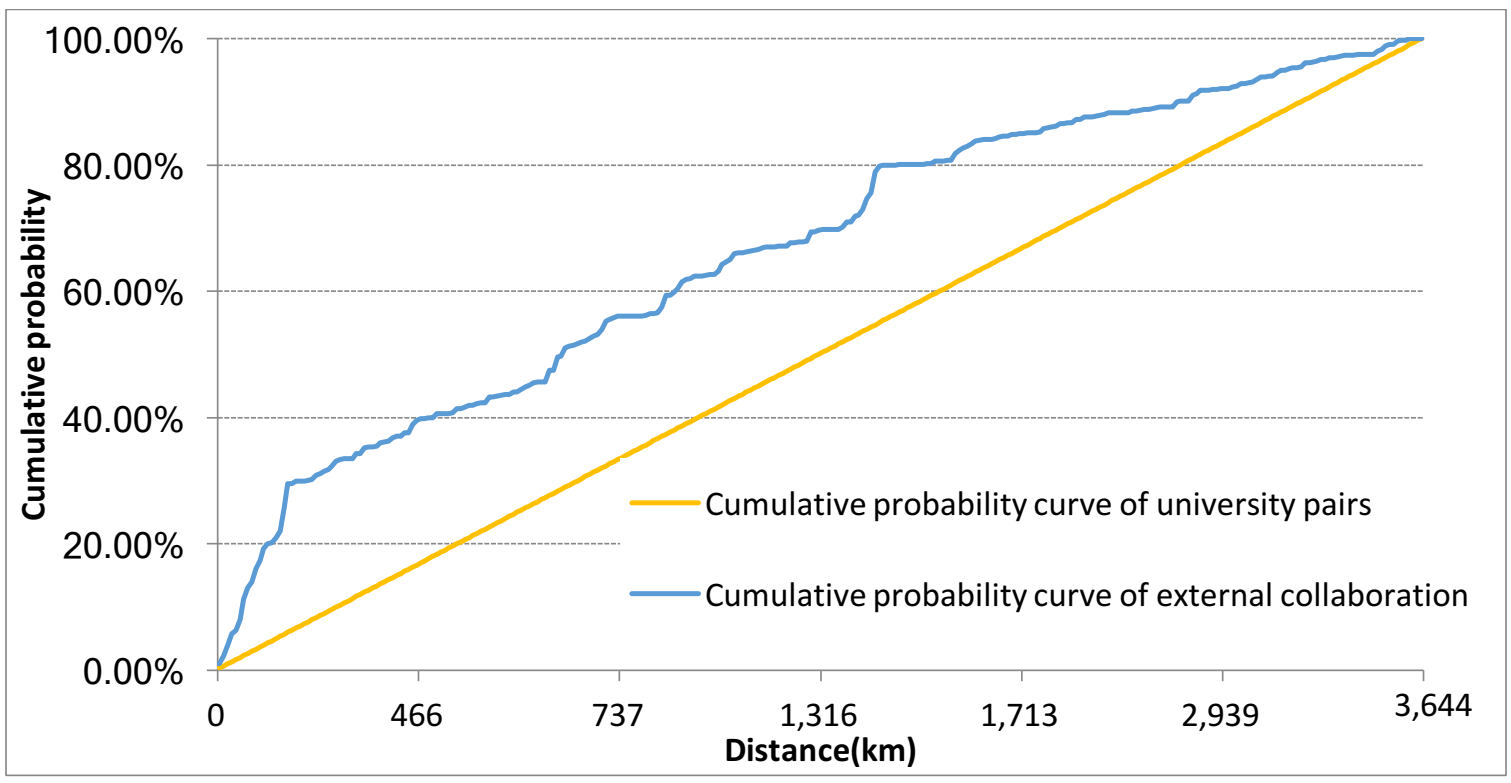

Figure 1 Cumulative probability curves of university pairs and external collaboration

\subsubsection{Australian university category by geographical region based on an onion model}

The onion model was used as a framework for describing an expanding or extending authorship collaboration of pairs of universities between several regions. The onion is a metaphor to illustrate the collaboration from a core region (referred to here as the eastern triangle link given its geographical positioning), gradually extending towards the outer circle. The onion diagram is presented as an Euler diagram (see Figure 2).

- The eastern triangle link region includes four cities: Melbourne, Sydney, Canberra and Brisbane. The four cities are the subsets of the eastern triangle link region. The external collaboration of pairs of universities was calculated between universities in different cities. For example, Canberra (1- Australian National University) - Sydney (2 - University of New South Wales),

- The regional link region includes regional universities around these four cities. It is the extension or exterior of the eastern triangle link region. The external collaboration of pairs of universities for the regional link is between exterior universities (i.e., regional universities) and interior universities (i.e., universities within the four cities).

- The eastern and southern link region includes universities in Adelaide and Northern Queensland. It is the extension or exterior of the regional link region and 
eastern triangle link. The external collaboration of pairs of universities for the eastern and southern link is between exterior universities (i.e., eastern and southern link universities) and interior universities (i.e., universities within the regional link and eastern triangle link).

- The outer circle link region includes universities in Perth and Darwin. It is the extension or exterior of the region of the eastern and southern link, the regional link and the eastern triangle link. The external collaboration of pairs of universities for the eastern and southern link is between exterior universities (i.e., outer circle link universities) and interior universities (i.e., universities within the eastern and southern link, the regional link and the eastern triangle link). The universities for each set in the onion model defined specifically for this study are listed in Table 1.

For these categories, the internal collaboration is defined as author collaboration within a university in the interior set, e.g. eastern triangle link region. External collaboration is defined as author collaboration between universities in the interior set and universities in the exterior set. We assume that Eastern triangle link is the core of the onion or the driving force of publication on the basis of overall publication outputs. As we gradually add a layer, such as the regional link region, to the onion, the smaller the external collaboration between universities in the interior set and universities in the exterior set is. We will test this assumption using our data.

Table 1 University list for the Euler diagram

\begin{tabular}{|c|c|c|c|}
\hline & \multicolumn{2}{|c|}{ Subsets } & $\begin{array}{l}\text { No. of External } \\
\text { collaboration of } \\
\text { university pairs }\end{array}$ \\
\hline \multirow[t]{2}{*}{$\begin{array}{l}\text { Eastern } \\
\text { triangle link }\end{array}$} & \multicolumn{2}{|c|}{$\begin{array}{l}\text { Four subsets: Melbourne }\left(18^{*}, 19,20,21\right) \text {, Sydney }(2,3, \\
\text { 4), Canberra (1) and Brisbane }(11,13,14) .\end{array}$} & \multirow[t]{2}{*}{$43 * *$} \\
\hline & The exterior set & The interior set & \\
\hline Regional link & $\begin{array}{l}\text { six regional universities }(5,6 \text {, } \\
\qquad 8,9,10,22)\end{array}$ & $\begin{array}{l}18,19,20,21,2,3,4 \\
1,11,13 \text { and } 14\end{array}$ & 66 \\
\hline $\begin{array}{l}\text { Eastern and } \\
\text { southern link }\end{array}$ & $\begin{array}{c}3 \text { Adelaide universities (15, } \\
\text { 16, 17) and James Cook } \\
\text { University (12) }\end{array}$ & $\begin{array}{l}5,6,8,9,10,22,18,19 \\
20,21,2,3,4,1,11,13 \\
\quad \text { and } 14\end{array}$ & 68 \\
\hline $\begin{array}{l}\text { Outer circle } \\
\text { link }\end{array}$ & $\begin{array}{c}3 \text { Perth universities }(23,24 \text {, } \\
25) \text { and Charles Darwin } \\
\text { University (7) }\end{array}$ & $\begin{array}{c}15,16,17,12,5,6,8,9 \\
10,22,18,19,20,21,2 \\
3,4,1,11,13 \text { and } 14\end{array}$ & 84 \\
\hline
\end{tabular}

* The number refers to a university, whose name can be seen in Figure 2.

** A pair of universities is universities from different subsets 


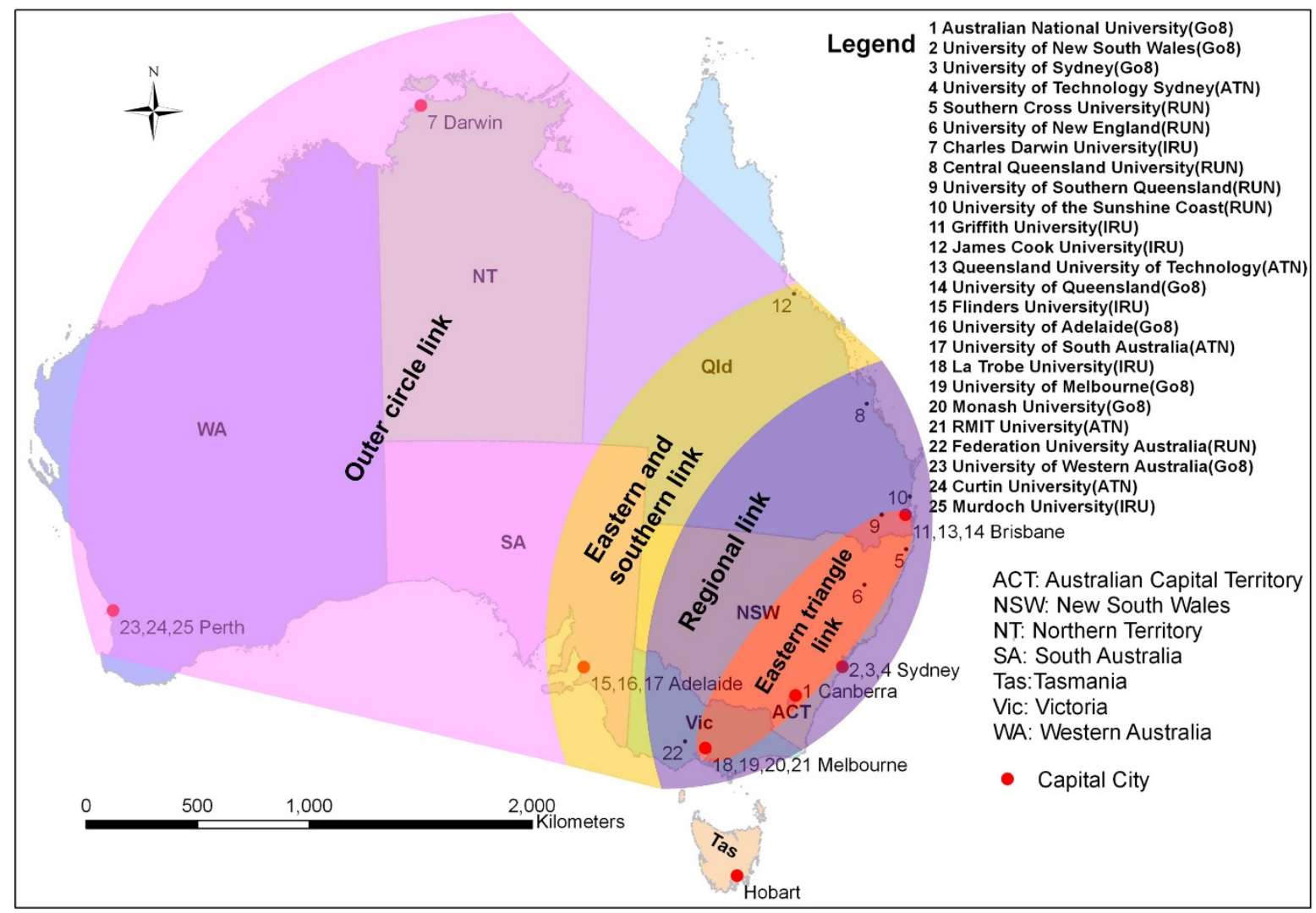

Figure 2 The Euler diagram of geographic regions and location of Australian Universities

\subsection{Analysis of relationship between distance and the collaboration of Australian} universities

The relationship between distance and the collaboration of Australian universities was analysed using correlation methods and the gravity model.

\subsubsection{Exploratory data analysis}

We calculated the average number of internal collaborations for each university based on publications, the number of external collaborations between two universities, and the average Euclidian distance between the main campuses of two universities for these three university categories including distance, geographical region and alliance type category and associated subcategories. The correlation between distance and the number of external collaborations between two universities was determined using IBM SPSS Statistics software version 23 (IBM Corp, 2013). We also mapped the spatial distribution of external collaboration between Australian universities with a threshold of the top $10 \%$ or more publications between universities using ArcGIS software (ESRI 2016). 


\subsubsection{Gravity model}

The gravity model has been widely used in investigations of the relationship between distance and scientific collaboration (for example, Acosta et al., 2011; Hoekman et al., 2010). The external scientific collaboration are count data that display over-dispersion and excess zeros. Here, we adopted the Zero-inflated Poisson (ZIP) regression model to estimate the external collaboration and zero contribution (Lambert, 1992, Lee et al., 2007, Plotnikova \& Rake, 2014, Sidone, Haddad \& Mena-Chalco, 2017). We assume that there is distance decay of external collaboration between universities: that is, collaboration between pairs of universities declines as the distance between them increases. In addition, we also assume that the stronger internal collaboration of universities and the total number of co-authored publication indicates greater external collaboration between pairs of universities. On the other hand, we investigated the effect of distance and university types, geographical region types on zero collaboration and external collaboration by estimating the models by university types and geographical regional types separately. The ZIP equation takes the form (Lambert, 1992):

In ZIP regression, the external collaborations $\mathbf{Y}=\left(Y_{l}, \ldots, Y_{n}\right)$ ' are independent and

$$
\begin{aligned}
& Y_{i j} \sim 0 \quad \text { with probability } p_{i j} \\
& \sim \operatorname{Poisson}\left(\lambda_{i j}\right) \quad \text { with probability } 1-p_{i j} \\
& \operatorname{Pr} .\left[Y_{i j}=0\right]=p_{i j}+\left(1-p_{i j}\right) \exp \left(-\lambda_{i j}\right) \\
& \operatorname{Pr} .\left[Y_{i j}=\lambda_{i j}\right]=\left(1-p_{i j}\right) \exp \left(-\lambda_{i j}\right) \lambda^{k} / k ! ; k=1,2,3, \ldots . .
\end{aligned}
$$

Moreover, the parameters $\lambda=\left(\lambda_{1}, \ldots \lambda_{n}\right)$ 'and $\mathbf{p}=\left(p_{1}, \ldots p_{n}\right)$ 'satisfy

$$
\begin{gathered}
\ln \left(\boldsymbol{\lambda}_{i j}\right)=\mathbf{B} \boldsymbol{\beta} \\
\boldsymbol{\lambda}_{i j}=\alpha_{1} \frac{M A S S_{i}^{\alpha_{2}} M A S S_{j}^{\alpha_{3}}}{D I S T A N C E_{i j}^{\alpha_{4}} U T_{i j}^{\alpha_{5}}} \\
\ln \left(\boldsymbol{\lambda}_{i j}\right)=\ln \alpha_{1}+\alpha_{2} \ln M A S S_{i}+\alpha_{3} \ln M A S S_{j}+\alpha_{4} \ln \operatorname{DISTANCE}_{i j}+\alpha_{5} \ln U T_{i j} \\
\operatorname{logit}(\mathbf{p})=\log (\mathbf{p} /(1-\mathbf{p}))=\mathbf{G} \boldsymbol{\gamma}
\end{gathered}
$$

For covariate matrices $\mathbf{B}$ and $\mathbf{G}$.

The covariates that affect the Poission regression and logit regression may not the same. In this study, we considered the following covariates for these two models.

$Y_{i j}$ is the number of external collaboration between the university $i$ and $j$.

$M A S S_{i}$ and $M A S S_{j}$ can be either $\mathrm{M}_{\mathrm{i}}$ and $\mathrm{M}_{\mathrm{j}}$ or $C_{i}$ and $C_{j}$ or both of them

$M_{i}$ or $M_{j}$ and $C_{i}$ or $C_{j}$ are the number of internal collaboration within the university $i$ and $j$ and the number of co-authored publication within the university $i$ and $j$.

$U T_{i j}$ are the type of universities in which co-authors within the university $\mathrm{i}$ and $\mathrm{j}$ affiliate to. To simplify the model, we only estimate the collaboration between the university i and $\mathrm{j}$ belonging to the same university alliance. 
- $U T_{i j}=1$ if two universities belongs to the Group of Eight Universities;

- $U T_{i j}=2$ if two universities belongs to Australian Technology Network;

- $U T_{i j}=3$ if two universities belongs to Innovative Research Universities;

- $U T_{i j}=4$ if two universities belongs to Regional University Network;

$U T 4_{i j}$ is a dummy variable, which is equal to one if the university alliance is the Regional University Network, otherwise it is equal to zero. We may use this variable for zeroinflated regression part of modelling, due to collaboration activities between regional universities being relatively less frequent than takes place with the other types of university alliances.

$d_{i j}$ is the geographical distance between the university $i$ and $j$.

$\alpha_{1}$ is a proportionality constant related to the type of the collaboration between universities.

$\alpha_{2}$ and $\alpha_{3}$ are a parameter inferring potential to generate external collaboration by $M A S S_{i}$ and $M A S S_{j}$. The $\alpha_{2}$ and $\alpha_{3}$ higher than one implies an exponential growth of the external collaboration of pairs of universities as the MASS grows. While the parameter that is close to zero indicates that MASS has a weak impact on the external collaboration.

$\alpha_{4}$ is the distance decay parameter, which shows the relationship between external collaboration of pairs of universities and their distance when all other determinants are constant. The higher the $\alpha_{4}$, the more important the distance or the steeper decline of external collaboration with distance.

$\alpha_{5}$ is a parameter inferring university alliance types.

In this analysis, we used the parameter of distance to understand the relationship between observed collaboration between universities and distance between universities when all other variables are constant. A high negative distance parameter indicates that distance is more likely to deter the collaboration between universities, while a distance parameter that is close to zero indicates that distance is a weak deterrent to collaboration. We also examined the role of institutional proximity in relation to external collaboration by the different university alliance groups.

\section{Results}

4.1 Ranking of internal and external collaboration between Australian universities within alliance groups

The findings for our examination of internal and external collaboration between Australian universities, indicate that generally the Go8 are the strongest in terms of academic publications (see Table 2 and Figure 5). This group has approximately 3.5 times the average sole authored publication per university and twice the average internal and external collaboration per 
university when compared to the ATN and IRU universities. Compared with the RUN universities, the Go8 has almost ten times the number of sole authored publication per university, eight times the average internal collaboration per university, and five times the average external collaboration per university. Internal collaboration is usually stronger than external collaboration. The IRU universities have a higher average number of sole authored publications per university than that of the ATN. However, the ATN has stronger internal and external collaboration than the IRU. The RUN universities are generally ranked low in all three areas (see Table 2).

Our analysis of individual universities indicates that the University of Queensland has the strongest internal collaboration compared to the other 24 universities, while Monash University has the highest total number of external collaborations (see Table 2). Sydney University was ranked as number one for the number of sole authored publications. As an ATN university, Queensland University of Technology stands out for its strong performance in internal collaboration, ranked at fifth, and external collaboration, ranked at eighth. Griffith University, in the IRU group, demonstrated a high level achievement in both sole authored publications (ranked eighth) and collaboration (internal collaboration ranked at sixth and external collaboration ranked fifth). The University of New England was the highest ranked in sole authored publications and internal collaboration among the RUN universities, especially its sole author publication numbers, which was ranked at 14 . For the external collaboration, University of Southern Queensland was ranked the highest among the RUN universities. 
Table 2 Number of sole authored publication and collaborations by 25 Australian universities

\begin{tabular}{|c|c|c|c|c|c|c|}
\hline University name & $\begin{array}{c}\text { Sole } \\
\text { authored } \\
\text { publicatio } \\
\text { n } \\
\text { numbers }\end{array}$ & $\begin{array}{c}\text { Sole } \\
\text { authored } \\
\text { publicatio } \\
\text { n } \\
\text { numbers } \\
\text { ranking } \\
\end{array}$ & $\begin{array}{c}\text { Internal } \\
\text { collabora } \\
\text { tion } \\
\text { numbers }\end{array}$ & $\begin{array}{c}\text { Internal } \\
\text { collabor } \\
\text { ation } \\
\text { ranking }\end{array}$ & $\begin{array}{c}\text { Total } \\
\text { external } \\
\text { collabora } \\
\text { tion } \\
\text { numbers }\end{array}$ & $\begin{array}{c}\text { Total } \\
\text { external } \\
\text { collabora } \\
\text { tion } \\
\text { ranking }\end{array}$ \\
\hline University of Queensland & 686 & 5 & 991 & 1 & 540 & 2 \\
\hline Monash University & 915 & 4 & 836 & 2 & 590 & 1 \\
\hline University of Melbourne & 1128 & 2 & 804 & 3 & 397 & 3 \\
\hline University of Sydney & 1381 & 1 & 785 & 4 & 316 & 4 \\
\hline Queensland University of Technology & 225 & 13 & 619 & 5 & 199 & 8 \\
\hline Griffith University & 387 & 8 & 483 & 6 & 290 & 5 \\
\hline Australian National University & 915 & 3 & 408 & 7 & 273 & 6 \\
\hline University of New South Wales & 646 & 6 & 310 & 8 & 195 & 9 \\
\hline James Cook University & 150 & 17 & 294 & 9 & 127 & 15 \\
\hline University of South Australia & 204 & 15 & 287 & 10 & 180 & 10 \\
\hline University of Western Australia & 328 & 9 & 280 & 11 & 171 & 11 \\
\hline Curtin University & 142 & 18 & 260 & 12 & 169 & 12 \\
\hline La Trobe University & 495 & 7 & 258 & 13 & 229 & 7 \\
\hline University of Technology Sydney & 276 & 10 & 190 & 14 & 112 & 17 \\
\hline University of Adelaide & 263 & 11 & 189 & 15 & 138 & 13 \\
\hline Flinders University & 242 & 12 & 179 & 16 & 118 & 16 \\
\hline RMIT University & 191 & 16 & 147 & 17 & 134 & 14 \\
\hline University of New England & 219 & 14 & 146 & 18 & 98 & 20 \\
\hline Murdoch University & 130 & 19 & 121 & 19 & 104 & 18 \\
\hline Southern Cross University & 38 & 22 & 96 & 20 & 82 & 21 \\
\hline University of Southern Queensland & 58 & 21 & 80 & 21 & 100 & 19 \\
\hline Charles Darwin University & 19 & 25 & 45 & 22 & 69 & 22 \\
\hline Federation University Australia & 95 & 20 & 44 & 23 & 26 & 24 \\
\hline University of the Sunshine Coast & 21 & 24 & 40 & 24 & 25 & 25 \\
\hline Central Queensland University & 28 & 23 & 23 & 25 & 40 & 23 \\
\hline University alliance categories & $\begin{array}{c}\text { Sole } \\
\text { authored } \\
\text { publicatio } \\
\text { n } \\
\text { numbers }\end{array}$ & $\begin{array}{c}\text { Ave sole } \\
\text { authored } \\
\text { publicatio } \\
\text { n } \\
\text { numbers } \\
\text { per uni } \\
\end{array}$ & $\begin{array}{c}\text { Internal } \\
\text { collabora } \\
\text { tion } \\
\text { numbers }\end{array}$ & $\begin{array}{c}\text { Ave } \\
\text { internal } \\
\text { collabor } \\
\text { ation } \\
\text { per uni }\end{array}$ & $\begin{array}{c}\text { External } \\
\text { collabora } \\
\text { tion } \\
\text { numbers }\end{array}$ & $\begin{array}{c}\text { Ave } \\
\text { external } \\
\text { collabora } \\
\text { tion per } \\
\text { uni }\end{array}$ \\
\hline Group of Eight Universities & 6262 & 783 & 4603 & 575 & 2620 & 328 \\
\hline Australian Technology Network & 1038 & 208 & 1503 & 301 & 794 & 159 \\
\hline Innovative Research Universities & 1423 & 237 & 1380 & 230 & 937 & 156 \\
\hline Regional Universities Network & 459 & 77 & 429 & 72 & 371 & 62 \\
\hline
\end{tabular}


Generally, distance between two universities and the number of external collaborations between two universities have a statistically significant linear relationship $(p=0.000<.005)$ (See Table 3). As the distance increases, the number of external collaborations decreases. However, this association is moderate $(\mathrm{r}=-0.31)$. In addition, we calculated the correlation coefficient $(r)$ between distance and external collaboration for each subcategory of these three categories. A moderate negative association between distance and collaboration within the Go8 subcategory was found to be statistically significant (-0.38). This relationship within other subcategories was not significant.

We compared this relationship for the category of distance, geographical regions and institutional alliances (see Table 3). In terms of distance, a statistically significant negative association between distance and external collaboration was confirmed $(r=-0.31)$, although the relationship is weak. Universities located within the same city $(<25 \mathrm{~km})$ are more likely to collaborate than universities located in different cities. This demonstrates that distance generally may be a barrier to external collaboration.

For the geographical region categories, generally, as regions extend from the core area, or as we add the layer to the onion, the number of and the distance between the pairs of universities gradually increase, while the average external collaboration numbers per university pair decreases from the eastern triangle link to the eastern and southern link, and then to the outer circle link. However, the regional link region had the lowest average distance per university pairs and relatively low average external collaboration per university pairs. This does not align with the general distance decay trend, but might indicate that other factors affect the external collaboration. For this case, we found that the regional link region also has the lowest average internal collaboration per university. We could suggest that the actual research strength of the university can also play an important role in collaboration.

For the university alliance categories, the RUN universities have the lowest internal collaboration, while their external collaboration within the RUN university network is the lowest. In contrast, external collaborations between two universities within the Go8 is highest and its internal collaboration is the strongest compared to other types of universities. This suggests that the type of institution and alliance group can also play an important role in encouraging collaboration (see Table 3 ).

Table 3. Number of internal and external collaboration by Australian universities by distance, region and institutional proximity

\begin{tabular}{|c|c|c|c|c|c|}
\hline & Categories & $\begin{array}{c}\text { Avg } \\
\text { distance } \\
\text { per uni } \\
\text { pair } \\
\text { (km) }\end{array}$ & $\begin{array}{c}\text { Avg internal } \\
\text { collaboration } \\
\text { per uni }\end{array}$ & $\begin{array}{c}\text { Avg external } \\
\text { collaboration } \\
\text { per uni pair }\end{array}$ & $\begin{array}{c}\text { Correlation } \\
\text { coefficient } \\
\text { between } \\
\text { distance and } \\
\text { external } \\
\text { collaboration }\end{array}$ \\
\hline All universities & & 1523 & 317 & 7.87 & $-0.31 * *$ \\
\hline \multirow{3}{*}{$\begin{array}{l}\text { Distance } \\
\text { categories } \\
(\mathrm{km})\end{array}$} & $0-25$ (with the same city) & 9 & / & 38.67 & 0.38 \\
\hline & $25-1400$ & 786 & I & 8.00 & 0.11 \\
\hline & $>1400$ & 2554 & I & 3.56 & 0.03 \\
\hline \multirow{2}{*}{$\begin{array}{l}\text { Geographical } \\
\text { region }\end{array}$} & Eastern triangle link & 858 & 530 & 15.70 & 0.17 \\
\hline & Regional link & 816 & 72 & 4.26 & -0.24 \\
\hline
\end{tabular}




\begin{tabular}{llrrrr} 
& Eastern and southern link & 1271 & 237 & 5.49 & -0.08 \\
& Outer circle link & 3036 & 177 & 3.65 & 0.01 \\
\hline \multirow{3}{*}{$\begin{array}{l}\text { University } \\
\text { type }\end{array}$} & Australian Technology Network & 1798 & 575 & 24.46 & $-0.38^{*}$ \\
& Innovative Research Universities & 2252 & 301 & 4.30 & 0.20 \\
& Regional Universities Network & 730 & 230 & 4.40 & -0.50 \\
\hline
\end{tabular}

* Correlation is significant at the 0.05 level (2-tailed). ** Correlation is significant at the 0.01 level (2-tailed).

\subsection{The spatial distribution of collaboration between Australian universities}

In this study, we calculated the percentage of university pairs and external collaboration by distance (see Figure 3). Generally, the percentage of external collaboration activity decreases as distance increases until distance reaches $2500 \mathrm{~km}$, then it rises as distance increases over $2500 \mathrm{~km}$. The percentage of university pairs by distance follows the similar spatial distribution pattern, except that the percentage of university pairs in the category of 500$1000 \mathrm{~km}$ is higher than that in the category of $0-500 \mathrm{~km}$, but the percentage of external collaboration in the category of $0-500 \mathrm{~km}$ is much higher than other distance categories. This means that it is not necessary that the higher percentage of university pairs leads to the higher percentage of external collaboration.

We also calculated the average external collaboration per university pair by distance (see Figure 3). Generally, the average external collaboration per university pair by distance decreases as distance increases until distance reaches $2500 \mathrm{~km}$. It then increases as distance increases to over $2500 \mathrm{~km}$.

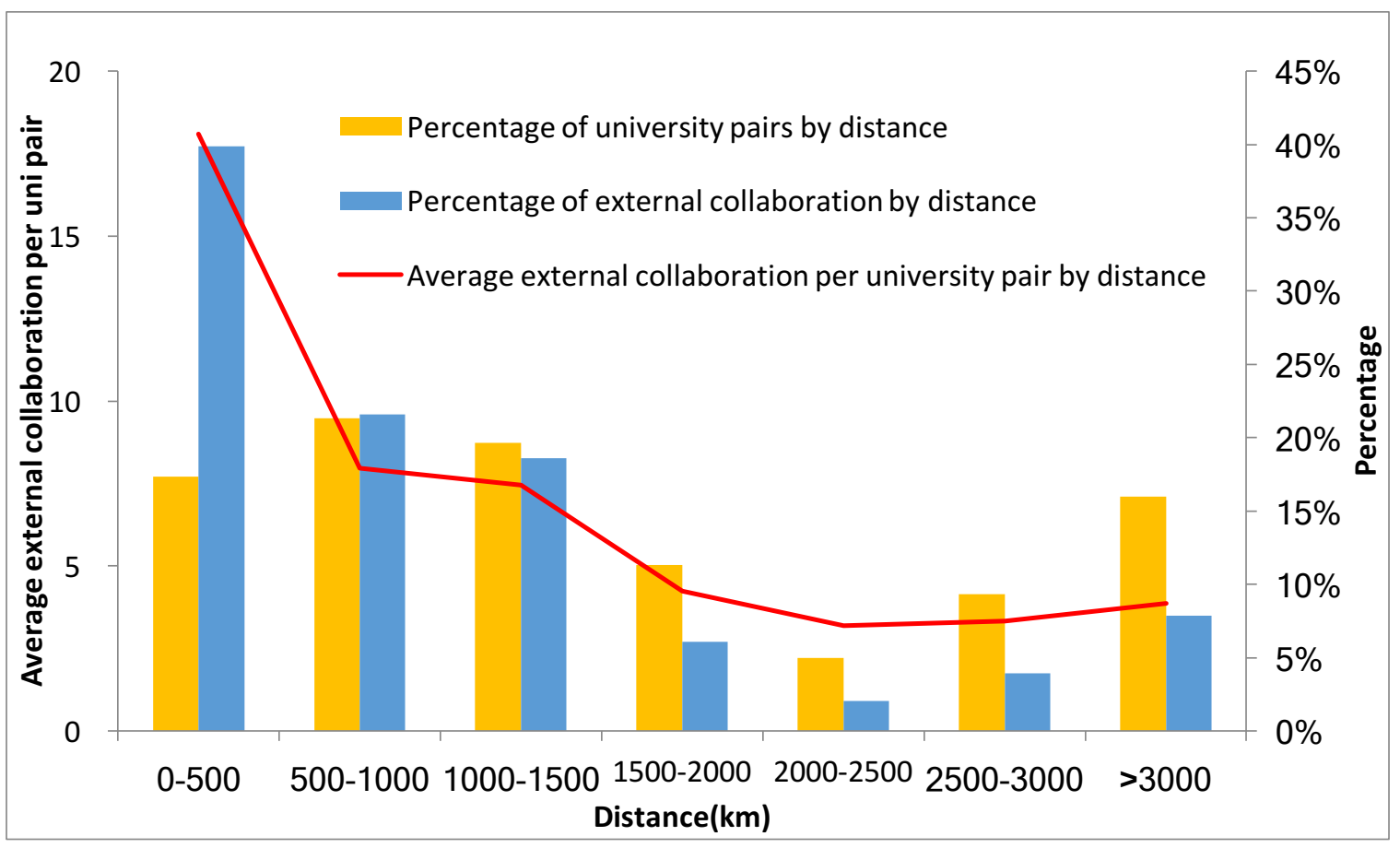

Figure 3 Average external collaboration per university pair by distance 
We focussed on universities where the number of collaboration outputs between universities was greater than 22 , which is the top $10 \%$ or more external collaboration. Thirty university pairs were identified and illustrated in Figure 4. These universities are mainly distributed in the southeast of Australia. Two small clusters appeared in the southwest and south Australia. All Go8 universities take part in the network, five are from the ATN, five are IRU universities, and one is from the RUN alliance. Ten pairs of universities are in the Go8 allicance only. Twenty-eight of 30 pairs involve Go8 universities. It appears then that the Go8 universities are the main driving force for collaboration between universities.

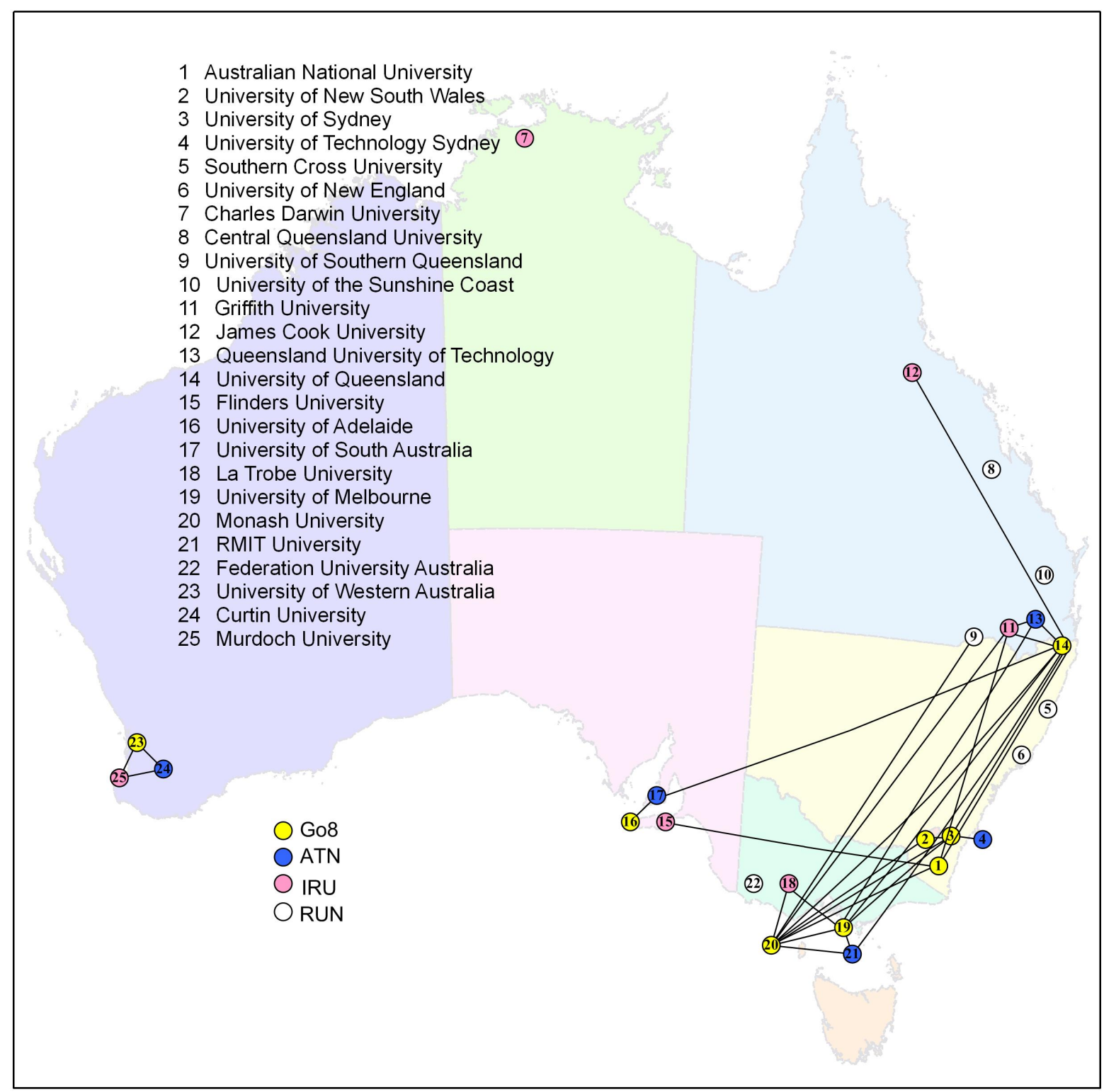

*The location of these universities on the map is only for illustration purpose. Some of them may not be completely accurate.

Figure 4. Universities with the number of external collaboration between universities greater than 22 
Monash University had the highest number of external collaborations (590) and collaborated with 25 other universities, while the University of Queensland was ranked as the second (540) and collaborated with 24 other universities (see Table 2). Nine universities were found to collaborate with both of these two universities with the number of collaborations more than 22 times (see Figure 4). Both of these universities have collaborated with 24 other universities (see Figure 5). Interestingly, the University of Southern Queensland is the only RUN university that has more than 22 external collaborations, and this collaboration is with Monash University, not universities that are closer in distance.

Another case that defies the distance decay pattern is the Australian National University, which has stronger collaborations with the University of Queensland, Monash University, Flinders University and Griffith University rather than the geographically closer universities in Sydney.

Based on the numbers of external collaboration between universities, we can categorise Australian universities into three collaboration networks:

- Strong university collaboration within region and cross regions: In the State of Victoria, strong university collaboration was seen. Four universities $(18,19,20$ and 21) not only collaborated with each other more than 22 times, but also with universities in the eastern triangle link region, especially with the University of Queensland. The State of Queensland also has a similar university network pattern, however, it is not as strong in terms of collaboration as in Victoria. The collaboration between universities becomes polarised by these two regions: Victoria and Brisbane.

- Strong university collaboration within a region but weak collaboration across regions: Three universities in WA had collaborations with each other more than 22 times. However, none of them have strong connections to the universities outside of WA.

- Weak university collaboration within a region but strong collaboration across regions: Universities in Sydney and Canberra are strongly linked to universities in other regions, but they had relatively weak connections within their own region.

- Weak university collaboration within a region and collaboration across regions: Only the University of South Australia and University of Adelaide collaborated more than 22 times within the region. The University of South Australia achieved this external collaboration with the University of Queensland as did Flinders University with the Australian National University. 


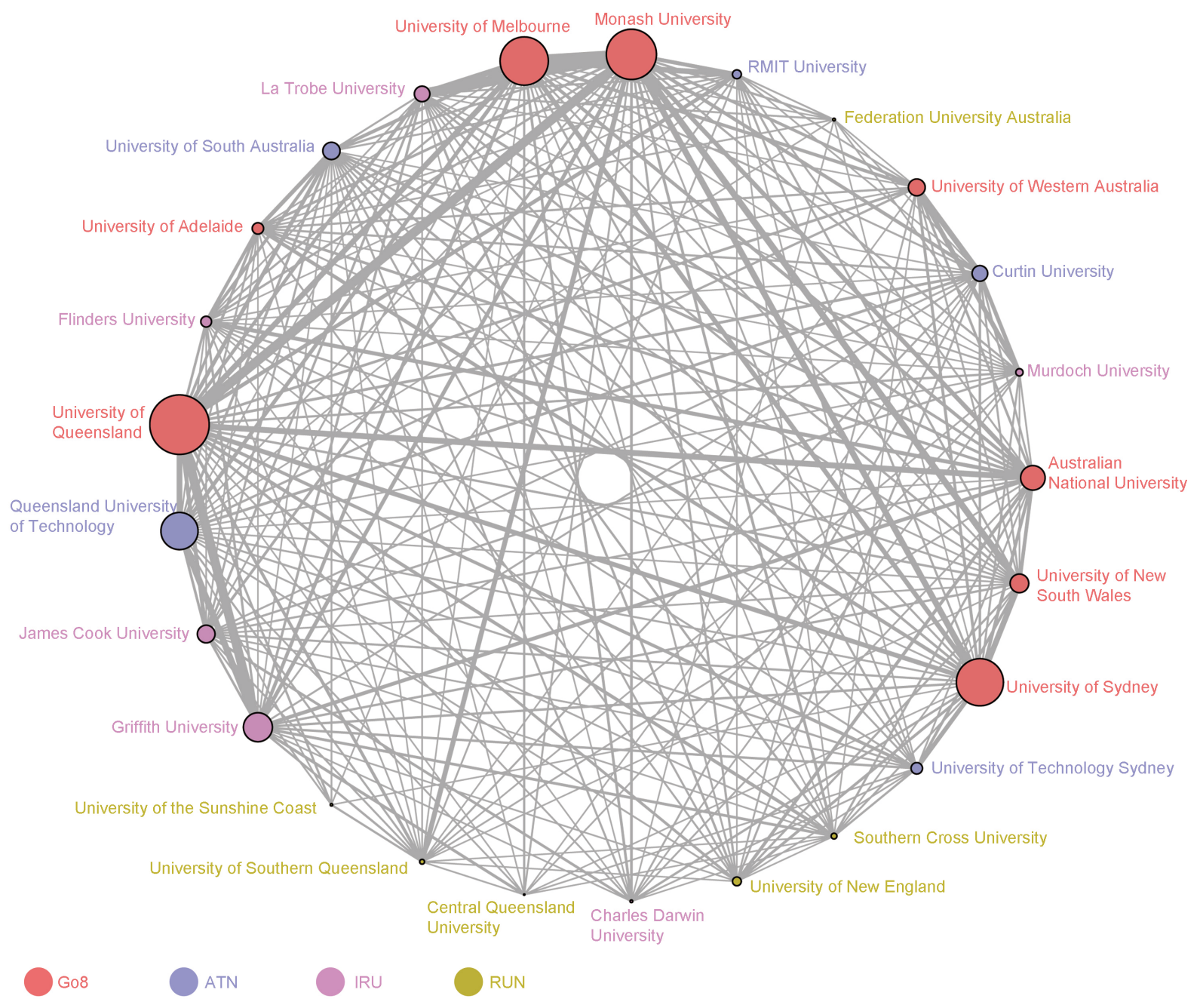

Figure 5 Number of internal and external collaboration of 25 Australian universities. (The size of circle and line represent the number of internal collaboration and external collaboration respectively)

\subsection{ZIP model for testing institutional alliance}

A ZIP model was developed for understanding the role of institutional proximity in relation to external collaboration by the different university groups (see Table 4). Using a chi-squared test on the difference of log likelihoods between the current model and a null model without predictors, we found that all of the predictors in both the count and inflation portions of the model are statistically significant $(8.921267 \mathrm{e}-186(\mathrm{df}=9)$. This means that the model fits the data significantly better than the null model.

For the Poisson regression model, distance and internal collaboration variables were found to be statistically significant in influencing external collaboration between universities. The log of distance has a weak negative impact on external collaboration $\left(\alpha_{4}=\exp (-0.1841)=0.8319\right.$ and $p=0.000<0.05)$. The number of co-authored publications has a weak positive influence on external collaboration $\left(a_{2}=\exp (0.0027)=1.003\right.$ and $a_{3}=\exp (0.0020)=1.002$ and $p=0.000$ $<0.05)$. The UT4 has odds of $0.49\left(a_{5}=\exp (-0.7115)=0.4909\right)$, implying odds of external 
collaborations between universities within the Regional University Network are lower than the baseline, which is external collaborations between universities within the Go8 university alliance.

For the zero-inflate model, the significant predictor of being in the 'zero publishing' class is the university type 4 . The odds of zero publication between authors in the Regional University Network is about 28 times higher than those in other types of university alliances.

Table 4. The results of ZIP models

\begin{tabular}{|c|c|c|c|}
\hline \multicolumn{4}{|c|}{ ZIP model (Institution proximity) } \\
\hline \multicolumn{2}{|c|}{ Poisson regression model part } & \multicolumn{2}{|c|}{ Zero-inflation model } \\
\hline Parameter & model A estimate (SE) & Parameter & model A estimate (SE) \\
\hline (Intercept) & $1.7411(7.5561 \mathrm{E}-13)^{* * *}$ & (Intercept) & $-3.5876(0.0 .000241)^{*}$ \\
\hline $\mathrm{C}_{\mathrm{i}}$ & $0.0027(2.00 \mathrm{E}-16)^{* * *}$ & $\begin{array}{l}\text { UT4 dummy } \\
\text { (RUN) }\end{array}$ & $3.3377(0.008872)^{*}$ \\
\hline $\mathrm{C}_{\mathrm{i}}$ & $0.0020(2.00 \mathrm{E}-16)^{* * *}$ & & \\
\hline UT2 (ATN) & $-0.1441(0.4543)$ & & \\
\hline UT3 (IRU) & $0.0818(0.6261)$ & & \\
\hline UT4 (RUN) & $-0.7115(0.0657)$ & & \\
\hline LnDistance & $-0.1841(1.03 \mathrm{e}-15)^{* * *}$ & & \\
\hline \multicolumn{4}{|l|}{ Statistical fit } \\
\hline Log-likelihood & -210.3 on $9 \mathrm{Df}$ & & \\
\hline chi-squared test & $8.921267 \mathrm{e}-186(\mathrm{df}=9)$ & & \\
\hline $\mathrm{N}$ & 68 & & \\
\hline Zero observations & 11 & & \\
\hline $\mathrm{AIC}$ & 7.30 & & \\
\hline
\end{tabular}

Signif. codes: $0{ }^{\prime * * * \prime} 0.001^{\prime * * \prime} 0.01^{\prime * \prime} 0.05^{\prime} . .^{\prime} 0.1^{\prime \prime} 1$

\section{Concluding remarks}

The intention of our research was to study the spatial distribution pattern of Australian universities in terms of HASS researcher collaborative practices (using co-authorship as a proxy) and to measure the impact of distance, geographical region and institutional alliance groupings on this collaboration within and between the universities. It contributes to the literature by distinguishing between the types of collaboration by Australian universities and by providing insights into Australian university network development.

According to the first Geographical law, everything is related to everything else, but things that are closer are more related or similar than things at a greater distance (Tobler 1970). In our investigation of HASS co-authorship between 25 Australian universities, distance was found to have a weak impact on external collaboration for the 300 university pairs $(r=-0.31)$. That is, as distance increases, the number of collaborations between universities decreases moderately. In a few cases, universities collaborated more intensively with universities 
further away than those in closer proximity. For example, the University of Southern Queensland collaborates with Monash University (where distance is $1311 \mathrm{~km}$ ) 34 times, eight times with Griffith University $(111 \mathrm{~km})$, five times for the Queensland University of Technology $(109 \mathrm{~km})$, and 16 times with the University of Queensland $(108 \mathrm{~km})$. In addition, we found that the number of average external collaboration per university pair shows a slight increase when the distance between universities is greater than $2500 \mathrm{~km}$. This is due to collaboration between universities in the outer circle link region and those in the eastern triangle link region.

Based on the number of external collaborations between universities, we can categorise Australian universities into four types of collaboration within a region and across regions. They are: 1) Strong university collaboration within region and across regions; 2) Strong university collaboration within a region but weak collaboration across regions; 3) Weak university collaboration within a region but strong collaboration across regions; and 4) Weak university collaboration within a region and collaboration across regions. These four university network development types suggest that instead of building a university network based on the similarity of the universities, it may be effective to establish a hierarchical structure of different types of universities within a region, which can make the most of location advantage in the region to encourage knowledge exchange within that region. The stronger network could attract more collaboration between networks as well.

University alliance type was also found to have a moderate association with collaboration, but for the Go8 group only. This was true of the descriptive analysis and the ZIP models. Our research into HASS co-authorship by the 25 universities, discovered that the Go8 universities are the main driving force of collaboration between universities. On the other hand, RUN universities have a statistically positive relationship to zero external collaboration.

For the ZIP regression models, we also identified a weak distance decay pattern for estimating non-zero external collaboration counts. However, no relationship was identified between distance and zero external contribution.

This study included only the 25 universities involved in the alliances - Group of Eight Universities (Go8), Australian Technology Network (ATN), Innovative Research Universities (IRU) and Regional Universities Network (RUN) - in order to identify factors affecting collaboration between universities. This is a limitation. Although these 25 universities are major universities in Australia, it would be interesting to include all Australian universities in the analysis. In addition, we chose 22 as a threshold in mapping external collaboration between universities, which only included the top 10 per cent of pairs. This number could be changed for different studies in the future.

This study is the tip of the iceberg and many further research questions can be asked. For example, we tested only one form of the onion model, which is the interaction between an exterior to interior set. The assumption is that the further a region is from the core region, i.e., the eastern triangle link region, the less collaboration between the universities in the exterior to those in the interior, due to the distance barrier. However, while distance was found to be one of the factors affecting collaboration, the strength of a university's research reputation may also play a role in this interaction. Future research could conduct additional analysis of 
collaboration within and between universities in different layers of the onion model to extend our understanding of influencing factors, such as cognitive and social dimensions.

\section{References}

Abramo, D., D'Angelo, C.A., \& Murgia, G. (2014). Variation in research collaboration patterns across academic ranks. Scientometrics 98, 2275-2294.

Acosta, M., Coronado, D., Ferrándiz, E., \& Leon, M. D. (2011). Factors affecting interregional academic scientific collaboration within Europe: The role of economic distance. Scientometrics, 87, 63-74.

ATN (2016). Australian Technology Network. https://www.atn.edu.au/.

Australian Education Network (2017). Groupings of Australian universities, Australian Universities.com.au. http://www.australianuniversities.com.au/directory/australianuniversity-groupings/ .

Australian Research Council (2015). International collaboration. http://www.arc.gov.au/international-collaboration

Beaver, D. deB (2001) Reflections on scientific collaboration (and its study): Past, present, and future. Scientometrics, 52(3), 365-77.

Bordons, M., \& Gómez, I. (2000). Collaboration networks in science, in B. Cronin \& H.B. Atkins (eds). The Web of Knowledge: A festschrift in honor of Eugene Garfield. Medford, New Jersey: American Society for Information Science.

Boschma, R.A. (2005). Proximity and innovation. A critical assessment. Regional Studies, $39(1), 61-74$.

Endersby, J. W. (1996). Collaborative research in the social sciences: Multiple authorship and publication credit. Social Science Quarterly 77, 375-392.

\section{ESRI (2016). ArcGIS Desktop: Release 10.5. Redlands, CA: Environmental Systems} Research Institute.

Evans, T.S, Lambiotte, R., \& Panzarasa, P. (2011). Community structure and patterns of scientific collaboration in Business and Management. Scientometrics, 89, 381-396.

Fernández, A., Ferrándiz, E., \& Leon, M. D. (2016). Proximity dimensions and scientific collaboration among academic institutions in Europe: The closer the better?

Scientometrics, 106, 1073-1092. 
Frenken, K., Hoekman, J., Kok, S., Ponds, R., van Oort, F. \& van Vliet, J. (2009). Death of distance in science: A gravity approach to research collaboration. In A. Pyka \& A. Scharnhorst (Eds.), Innovation Networks, Understanding Complex Systems (pp. 43-57). Berlin: Springer-Verlag.

Glänzel, W., \& Schubert, A. (2005). Analysing scientific networks through co-authorship. In H.F. Moed, W. Glänzel \& U. Schmoch (eds). Handbook of quantitative science and technology research. New York: Kluwer.

Grabher \& Ibert, (2014). Distance as asset? Knowledge collaboration in hybrid virtual communities. Journal of Economic Geography, 14, 97-123.

Haddow, G., Xia, J., \& Willson, M. (2017). Collaboration in the humanities, arts and social sciences in Australia. Australian Universities' Review, 59(1), 24-36.

Hicks, D. (1999). The difficulty of achieving full coverage of international social science literature and the bibliometric consequences. Scientometrics 44, 193-215.

Hicks, D. (2005). The four literatures of social sciences, In H.F. Moed, W. Glänzel \& U. Schmoch (eds). Handbook of quantitative science and technology research. New York: Kluwer.

Hoekman, J., Frenken, K. and Tijssen, R. J. W. (2010). Research collaboration at a distance: Changing spatial patterns of scientific collaboration in Europe. Research Policy, 39, 662-73.

Hoekman, J., Frenken, K., \& van Oort, F. (2009). The geography of collaborative knowledge production in Europe. Annals of Regional Science, 43, 721-738.

IBM Corp (2013). IBM SPSS Statistics for Windows, Version 22.0. Armonk, NY: IBM Corporation.

IRU (2016). Innovative Research University. https://www.iru.edu.au .

Katz, J.S. (1994). Geographical proximity and scientific collaboration. Scientometrics, 31, $31-43$.

Katz, J.S. \& Martin, B.R. (1997). What is research collaboration? Research Policy, 26(1), 118.

Lambert, D. (1992). Zero-inflated Poisson regression, with an application to defects in manufacturing. Technometrics, 34(1), 1-14.

Larivière, V., Gingras, Y., \& Archambault, É. (2006). Canadian collaborative networks: A comparative analysis of the natural sciences, social sciences and the humanities.

Scientometrics, 68, 519-33.

Laudel, G. (2002). What do we measure by co-authorships? Research Evaluation, 11, 3-15. 
Lee, Y. G., Lee, J. D., Song, Y. I., \& Lee, S. J. (2007). An in-depth empirical analysis of patent citation counts using zero-inflated count data model: The case of KIST. Scientometrics, 70(1), 27-39.

Lorigo, L. \& Pellacini, F. (2007). Frequency and structure of long distance scholarly collaborations in a physics community. Journal of the American Society for Information Science and Technology, 58(10), 1497-1502.

Luukkonen, T., Persson, O., \& Silvertsen, G. (1992). Understanding patterns of international scientific collaboration. Science, Technology \& Human Values 17, 101-126.

Marshakova-Shaikevich, I. (2006). Scientific collaboration of new 10 EU countries in the field of social sciences. Information Processing \& Management 42, 1592-1598.

Moed, H. F. (2005). Citation analysis in research evaluation. Dordrecht: Springer.

Ossenblok, T.L.B., Verleysen, F.T., \& Engels, T.C.E. (2014). Co-authorship of journal articles and book chapters in the social sciences and humanities (2000-2010). Journal of the Association for Information Science and Technology 65, 882-897.

Pallot, M., Martinez-Carreras, M.A., \& Prinz, W. (2010). Collaborative distance: A framework for distance factors affecting the performance of distributed collaboration. International Journal of e-Collaboration, 6(2), 1-32.

Pan, R.K., Kaski, K., \& Fortunato, S. (2012). World citation and collaboration networks: uncovering the role of geography in science. Scientific Reports, 2, 902, 1-7.

Plotnikova, T., \& Rake, B. (2014). Collaboration in pharmaceutical research: exploration of country-level determinants. Scientometrics, 98(2), 1173-1202.

Ponds, R., Van Oort, F.G., \& Frenken, K. (2007). The geographical and institutional proximity of scientific collaboration networks. Papers in Regional Science, 86, 423-443.

RUN (2016) Regional Universities Network. http://www.run.edu.au.

Scherngell, T. \& Hu, Y. (2011). Collaborative knowledge production in China: Regional evidence from a gravity model approach. Regional Studies, 45(6), 755-772.

Sidone, O.J.G., Haddad, E.A., \& Mena-Chalco, J.P. (2017). Scholarly publication and collaboration in Brazil: The role of geography. Journal of the Association for Information Science \& Technology, 68(1), 243-258.

Sonnenwald, D.H. (2007). Scientific collaboration. Annual Review of Information Science and Technology, 41(1), 643-681.

The Royal Society (2011). Knowledge, Networks and Nations: Global scientific collaboration in the 21st century, RS Policy document 03/11

Tobler W., (1970) A computer movie simulating urban growth in the Detroit region. Economic Geography, 46(2): 234-240. 
Turner, G., \& Brass, K. (2014). Mapping the humanities, arts and social sciences in Australia. Canberra: Academy of the Humanities. Retrieved from http://www.humanities.org.au/PolicyResearch/Research/MappingtheHumanitiesArtsSoci alSciences.aspx

Waltman, L., Tijssen, R.J.W., van Eck, N.J. (2011). Globalisation of science in kilometres. Journal of Informetrics, 5, 574-582. 